\title{
Digital Innovation and Incubators: A Comparative Interview Study from the Perspective of the Automotive Industry
}

\author{
Anders Hjalmarsson Jordanius \\ RISE Viktoria \& \\ University of Borås, Sweden \\ anders.hjalmarsson@ri.se
}

\author{
Gustaf Juell-Skielse \\ RISE Viktoria \& \\ Stockholm University, Sweden \\ gjs@dsv.su.se
}

\author{
Aravind Kailas \\ Volvo Group North America, \\ U.S.A. \\ aravind.kailas@,volvo.com
}

\begin{abstract}
As non-corporate (herewith referred to as "independent") incubators gain in popularity for propelling digital innovation, traditional automotive firms have set up in-house incubators (herewith referred to as "corporate") to accelerate innovation without disrupting too much the inherent organizational structures and corporate cultures. The overarching objective is to establish the expected benefits for automotive firms from independent incubators when organizing corporate incubators. Using a comparative interview study, ten successful independent incubators in North America are discussed in terms of their ability to provide support in the digital domains. Our work has resulted in novel operating models for categorizing incubators to describe variations in focus areas and support for digital innovation. The results sheds light on how corporate incubators (internal to automotive firms) have the potential to shield digital ventures from the complexities of large and traditional establishments, and to promote interactions with other business units within the firm when performing digital innovation.
\end{abstract}

\section{Introduction}

The prospects of digitalisation [1] in the automotive industry are enormous with technology concepts such as autonomous driving, connected vehicles, and new business models [2]. But digital innovation [3] has proven difficult for Original Equipment Manufacturers (OEMs) due to complex organizational structures, corporate cultures and technological inertia associated with the automotive industry [4]. To overcome these challenges, OEMs have started setting up corporate incubators and accelerator programs to engage in digital ventures with external startup companies (herewith referred to as startups) [5].

Most commonly, OEMs have engaged startups to channel "outside-in" type of open innovations into their corporate setups [6]. Companies have also collaborated with startups to transform them into "engines of corporate innovation" [7, p.68]. One such example is BMW who built its own corporate incubator (called the BMW Startup Garage) to attract external software-based startups [8].

Despite the growing literature on independent incubators and their focus on information and communication technology-based ventures [9], it is still unclear how they support and accelerate digital innovation in OEMs $[5,10]$. The existing literature on corporate incubators is limited [11], and therefore motivates an investigation of how independent incubators support digital innovation. This to strengthen our understanding how corporate incubators may be improved to provide digital innovation support.

With this in mind, the following research question becomes very relevant: How is digital innovation championed by independent incubators?

Understanding and answering the aforementioned question helps to not only characterize independent incubators in terms of their ability to drive digital innovation, but also sheds light on how automotive firms can leverage corporate incubators to enhance "outside-in" type of innovation activities by engaging in digital ventures with external startups.

The paper is organized in seven sections. In Section 2 , the challenges for digital innovation in the automotive industry and key concepts for analyzing digital innovation in incubators are operationalized in an analysis framework. Section 3 presents the research methodology. The results of the comparative interview study are presented in Section 4, and our novel models for characterizing independent incubator operations is introduced in Section 5. The results are discussed in Section 6 , followed by conclusion and directions for future research in Section 7.

\section{Conceptual Basis}

In this section, three key concepts are explained digital innovation, digital innovation in the automotive industry, and incubators as an option for automotive OEMs to pursue digital innovation and collaborate with external startups.

\subsection{Digital Innovation}

Digital innovation is the socio-technical phenomenon of using information and communication 
technologies to create new market offerings, processes, or models [3]. By cleverly gleaning and adopting the logic from an existing physical implementation, a digital solution can become versatile and flexible, thereby providing a variety of reprogrammable functions $[1,12,13]$. Also, digital solutions can be embedded in physical products (e.g. automobiles) to make them more "intelligent." Digital solutions or products typically consist of several loosely coupled layers so that "digital components" can be easily reconfigured or applied to other domains as identified by the business needs [13,14].

According to Henfridsson et al. [15], the value from digital innovation can be created and realized in diverse applications. These value spaces consist of evolving networks of interlinked digital resources $(D R)$. By connecting digital resources within or between value spaces, actors can assign meaning and function, depending on the context, along value paths. A key activity in the value spaces framework is the recombination of digital resources both in design, by firms when creating offers to customers, and in use, when users combine digital resources to create value in the context they operate [15]. It requires firms to be cognizant of the customers' role when it comes to tapping the full potential of one's digital resources.

The nature of digital solutions and composition of digital products challenge key assumptions about innovation management [3]. Because functions of digital resources can vary across value spaces, and can be postponed to the point of use [15], the design spaces may be open during the complete life cycle of digital resources [10]. The modular and layered digital product structures [14] promote doubly distributed organization logic [1], where companies part of complex business ecosystems [16] realize novelty through the recombination of digital resources used by firms and users [15].

Digital innovation differs from classic views on innovation in that growth is measured in user base rather than customer base and that some digital ventures are able to scale much faster than industrial companies have been able to do [13]. Huang et al. [13] suggest that rapid scaling of digital ventures is due to three mechanisms - data-driven operations, instant releases, and swift transformations. In short, this implies that digital innovation builds on the use of data to identify new market opportunities, rapid and iterative product launches, and the ability to quickly adapt offerings to new contexts and value spaces.

\subsection{Digital Innovation in the Auto Industry}

Vehicles are becoming computing platforms for networks, services and content and the opportunities for digital innovation are intriguing [17]. But digital innovation in the automotive industry has proven to be problematic [4]. Juell-Skielse and Hjalmarsson [5] identify three broad problem areas of digital innovation in the automotive industry: innovation process, product marketing as well as leadership and organization. Based in empirical research they found that closed and top-down innovation processes with a focus on intellectual property (IP) rights make it difficult for established automotive firms to collaborate with external digital ventures. A fear of losing control of the product and restrictive assessment of digital resource make product marketing demanding for startups and a lack of digital knowledge and complex decision processes hinder established firms to lead and organize digital innovation effectively. Traditionally, innovation in the automotive industry is not an open process [18], but extremely streamlined with a high emphasis on IP rights [19], and designs frozen prior to production [10]. Because the values resulting from digital innovations are created in evolving networks [15], incumbent OEMs must emphasize innovation collaboration to reach out to external ecosystems [10].

The vehicle is divided in well-established subsystems with a shared responsibility for innovation between OEMs and suppliers [20] that tends to mirror the structure of the vehicle [21]. This division is favourable from a production perspective and the innovation processes are designed to support the industrialization of ideas in a so-called performance engine [22]. However, during major technology shifts that impact several vehicle subsystems, the rigid organizational ramifications and the silo between component suppliers and vehicle manufacturers [23] impede innovation and speed of adoption.

Organizations that have less structured knowledge flows are generally better suited to make use of innovations [24]. To make knowledge flow more freely in incumbent OEMs there is a need to change innovation focus from products and specific end user problems to process [10]. However, this may create challenges such as conflicting time horizons and resource distribution across means-ends [10].

Incumbents often possess the resources and routines necessary to execute business models efficiently [7]. But when performing digital innovation OEMs have to change the way innovation governance is performed. New managerial systems are needed that balance openness-closeness, flexibility-control, provide incentives to co-create, and forms enabling validation and cost control [10]. Established mechanisms need to be transformed so that process is controlled, but not to the expense of reducing the generative capability required to perform digital innovation; e.g. new ways of working, involvement of external developers, adopting digital skills. 


\begin{tabular}{|c|c|c|}
\hline \multicolumn{2}{|r|}{ Unit of analysis } & What level of support does the incubator provide to: \\
\hline \multirow{3}{*}{ 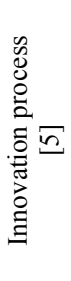 } & Recombination [15] & $\begin{array}{l}\text { - Generate value paths through recombination? } \\
\text { - Utilize available digital resources for recombination? } \\
\text { - Capture connections from other actors, i.e. path channeling? }\end{array}$ \\
\hline & $\begin{array}{l}\text { Digital resources (DR) } \\
{[15]}\end{array}$ & $\begin{array}{l}\text { - Design a digital resource that captures value from other digital resources? } \\
\text { - Design a digital resource that creates value to other digital resources? } \\
\text { - Design a digital resource that maximizes the number of value connections? }\end{array}$ \\
\hline & Value space [15] & $\begin{array}{l}\text { - Define the relevant value space? } \\
\text { - Identify multiple / alternative value spaces? }\end{array}$ \\
\hline \multirow{3}{*}{ 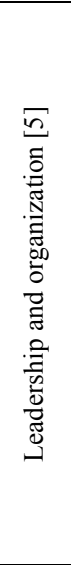 } & Innovation focus [10] & $\begin{array}{l}\text { - Focus on the process of innovation rather than the products? } \\
\text { - Focus on design patterns rather than specific end user problems? } \\
\text { - Provide generative products with generic rather than specific functionality? } \\
\text { - Delay decision making to avoid to freeze designs? } \\
\text { - Avoid prioritizing innovation based on internal resource availability? } \\
\text { - Support and commit to innovation rather than existing relationships with established large suppliers? }\end{array}$ \\
\hline & $\begin{array}{l}\text { Innovation collaboration } \\
{[10]}\end{array}$ & $\begin{array}{l}\text { - Reach out to external ecosystems? } \\
\text { - Mobilize differentiated and uncoordinated audiences? } \\
\text { - Enhance the ability to absorb knowledge about digital technologies and digital innovators? } \\
\text { - Boost the ability to coordinate digital enterprises that crosses functional and organizational boundaries? }\end{array}$ \\
\hline & Governance $[10]$ & $\begin{array}{l}\text { - Balance openness and control? } \\
\text { - Balance access to back-end systems? } \\
\text { - Balance co-creation and formal contracts? } \\
\text { - Manage shifts in identity and organizational culture to balance tensions between old and new structures? } \\
\text { - Manage independent developers? } \\
\text { - Develop internal and attract external digital skills? }\end{array}$ \\
\hline \multirow{3}{*}{ 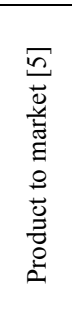 } & $\begin{array}{l}\text { Data-driven operation } \\
{[13]}\end{array}$ & $\begin{array}{l}\text { - Profile actors through data-driven activities? } \\
\text { - Assess innovation risks through data-driven activities? } \\
\text { - Monitor the customer base through data-driven activities? }\end{array}$ \\
\hline & Instant release [13] & $\begin{array}{l}\text { - Launch the digital resource? } \\
\text { - Concurrently trial the digital resource? } \\
\text { - Reactively modify the digital resource? }\end{array}$ \\
\hline & Swift transformation [13] & $\begin{array}{l}\text { - Conceptualize the digital resource for a new business context? } \\
\text { - Identify novel benefits of a digital resource for existing and/or new customers? } \\
\text { - Define (or re-define) the identity of the joint-venture? }\end{array}$ \\
\hline
\end{tabular}

Table 1. The analysis framework.

\subsection{Incubators and Accelerator Programs}

The basic goal of an incubator is to support and grow emerging ventures [9]. Incubators are defined as "organizations that support the establishment and growth of new businesses with tangible (e.g., space, shared equipment and administrative services) and intangible (e.g., knowledge, network access) resources during a flexible period and are funded by a sponsor (e.g., government or corporation) and/or fund themselves taking rent (or less frequently equity) from incubatees" [11, p.13]. The basic process in an incubator could be described in three phases - search and selection, business support, and mediation [11].

Using the above definition, incubators can be broadly classified into public or privately-owned. The privately-owned incubators come in two varieties corporate incubators that exist and operate within the firm, and independent incubators that are external to corporate firms [25]. Independent incubators are independent businesses focused on creating and growing startups. Established firms set up corporate incubators for open innovation to combine the incumbent firm's ability to efficiently execute a business model with the flexibility of the startup [7]. Corporate incubators can be designed to support both "inside-out" and "outside-in" types of innovations.

In order for corporate incubators to succeed, Kohler [6] identified a few themes. Separating the incubator from the corporation is important to shield it (and its ventures and startups) from corporate complexities (that result in slow decision-making) to not lose momentum. It is vital to designate "champions" who can coach and educate startups, tackle corporate complexities, and most importantly, connect into the right stakeholder groups within the corporation. Another important feature of corporate incubators is their networking capabilities to foster partnerships among startups and across companies [25], and to make the incubator part of a large ecosystem, outside the group of incubates $[26,6]$.

Corporate involvement with the startups can vary significantly [7]. On one hand, established firms can invest in startups for equity. This may mean more resources for the startup while hampering its ability to 
act on its own. On the other hand, established firms can support startups by partnering with independent incubators. In the middle, there are corporate incubators that do not involve corporate ownership, while offering greater flexibility and speedier access to a variety of new ventures. However, there is the possibility that not all new ventures may align with the corporate goals. In an attempt to combine digital entrepreneurship with corporate setups, established OEM within the automotive industry have begun to establish corporate incubators like the BMW Startup Garage and Daimler's Startup Autobahn.

In this paper we explore how digital innovation is championed by independent incubators to provide insights how corporate incubators within the automotive industry could be improved to facilitate digital innovation catalyzed by startups. This investigation is motivated by the fact that independent incubators are not bound by the legacy of organizational setups in large firms (e.g., automotive industry), and the limited understanding (within large firms) of the way startups operate [27].

Based on the conceptual investigation in the previous sub-sections an analysis framework has been developed to explore how independent incubators leverage digital innovation. The framework is organized with three themes and nine units. Keeping in mind the objective of learning how automotive firms can leverage corporate incubators to improve "outsidein" type of digital innovation, the three themes were based on Juell-Skielse and Hjalmarsson's classification of problem areas (as in [5]) and units (based on [10, 13, 15]) as shown in Table 1 . The table also includes a set of questions for understanding how incubators support digital innovation to analyze along each unit. This provides an operationalization of the key concepts (in italics) about digital innovation explored in section 2.1 and 2.2

\section{Research Methodology}

A comparative interview study approach has been used to characterize how independent incubators drive digital innovation. The study is a part of an action design research [31] project that involves ${ }^{1}$ two OEMs (Volvo Group and Volvo Car Corporation), three Tier1 suppliers (Ericsson, Veoneer, and Combitech), several startups, and a research institute (RISE Viktoria) (as described in [5]). The project builds on the idea to design and evaluate an organization for collaborating with startups that aim to provide value to the automotive industry triggered by field problems [5].

\footnotetext{
${ }^{1}$ SHOP is partially funded by Sweden's innovation agency Vinnova under Agreement Number: 2016-03189.
}

A total of ten independent incubators in North America (Canada and USA) were selected for the comparative interview study. A "systematic comparison-focused technique labeled criterion-based sampling" (as described in [30]) was used to select the cases. The selection criteria were access (to the incubator) and focus (that the incubator specialize in mobility tech startups; at least as one area). Each independent incubator was visited and interviewed inperson during spring 2018. Table 2 provides a brief overview over the incubators.

The interviews followed the response approach (as described in [29]), where interview guidelines were established, but with the flexibility that the interviewer may adapt slightly depending on the interviewee. The guidelines were developed using the analysis framework described in Table 1. With the interviewee consent, the interviews were also voice recorded. In situations where this was not possible, the interviewer took down copious notes that were subsequently compiled into a data log for each incubator visit. Other insights from the conversations during the incubator visits provided additional data for analysis (i.e. texts, audio and video material, provided by the incubators). E-mails were occasionally used to clarify points that emerged during transcriptions and the analysis.

\begin{tabular}{|c|c|}
\hline Case & About \\
\hline $\begin{array}{l}\text { Communitech (CT), } \\
\text { Waterloo, Canada }\end{array}$ & $\begin{array}{l}\text { Founded in } 1997, \text { CT is a technology } \\
\text { accelerator that also business development. } \\
\text { It covers multiple verticals and is sponsored } \\
\text { by membership fees as well as regional } \\
\text { funding won in competition. }\end{array}$ \\
\hline $\begin{array}{l}\text { Creative } \\
\text { Deconstruction Lab } \\
\text { (CDL), Toronto, } \\
\text { Canada }\end{array}$ & $\begin{array}{l}\text { Founded in } 2012, \text { CDL is a business } \\
\text { accelerator, including mentorship, and } \\
\text { raising capital. It covers multiple verticals } \\
\text { and is supported by private sector } \\
\text { memberships. }\end{array}$ \\
\hline $\begin{array}{l}\text { Automation Alley } \\
\text { (AA), Troy, MI, } \\
\text { USA }\end{array}$ & $\begin{array}{l}\text { Founded in 2011, AA is a cluster-driven } \\
\text { forum for economic development in MI. It } \\
\text { covers multiple verticals to drive the } \\
\text { economy in MI. It is supported by private } \\
\text { and public agencies in MI. }\end{array}$ \\
\hline $\begin{array}{l}\text { Techstars Mobility } \\
\text { (TM), Detroit, MI, } \\
\text { USA }\end{array}$ & $\begin{array}{l}\text { TM was founded in } 2006 \text {, but established in } \\
\text { Detroit in } 2014 \text {. It is a business accelerator } \\
\text { with a venture wing that targets one single } \\
\text { vertical (mobility). It is supported by private } \\
\text { sector memberships and an equity stake } \\
\text { provided upfront by the startup. }\end{array}$ \\
\hline $\begin{array}{l}\text { Sente Link (SL), } \\
\text { Chicago, IL, USA }\end{array}$ & $\begin{array}{l}\text { Founded in 2008, SL is a business } \\
\text { accelerator with a corporate onboard } \\
\text { program that aims to facilitate international } \\
\text { startups to scale in the USA. It covers } \\
\text { multiple verticals of which one is mobility. } \\
\text { It is supported by private sector } \\
\text { memberships and an equity stake provided } \\
\text { upfront by the startup. }\end{array}$ \\
\hline $\begin{array}{l}\text { Plug and Play Tech } \\
\text { Center (PnP), } \\
\text { Sunnyvale, CA, } \\
\text { USA }\end{array}$ & $\begin{array}{l}\text { Founded in 2006, PnP offers technology } \\
\text { accelerator, corporate innovation } \\
\text { consultancy, and venture capital services. It } \\
\text { covers multiple verticals. It is supported by } \\
\text { private sector memberships and may take an }\end{array}$ \\
\hline
\end{tabular}




\begin{tabular}{|c|c|}
\hline & $\begin{array}{l}\text { equity stake if membership partners } \\
\text { advocate this. }\end{array}$ \\
\hline $\begin{array}{l}\text { Motus Ventures / } \\
\text { FKA SV (MV } \\
\text { FKA), Redwood } \\
\text { City, CA, USA }\end{array}$ & $\begin{array}{l}\text { Founded in 2017, MV FKA is a technology } \\
\text { accelerator with a venture capital. It also is a } \\
\text { partnership between a VC firm and a } \\
\text { research institute that target a Single narrow } \\
\text { vertical (autonomous systems). It is } \\
\text { supported by private sector memberships } \\
\text { and an equity stake in the startup. }\end{array}$ \\
\hline $\begin{array}{l}\text { Nordic Innovation } \\
\text { House (NIH), Palo } \\
\text { Alto, CA, USA }\end{array}$ & $\begin{array}{l}\text { Founded in } 2011, \text { NIH provides business } \\
\text { accelerator programs, and an office } \\
\text { environment with community in the Silicon } \\
\text { Valley for startups from the Nordic countries } \\
\text { in Europe. It covers multiple verticals. } \\
\text { Supported by Nordic private sector and } \\
\text { governmental memberships. }\end{array}$ \\
\hline $\begin{array}{l}\text { Los Angeles } \\
\text { Cleantech Incubator } \\
\text { (LACI), Los } \\
\text { Angeles, CA, USA }\end{array}$ & $\begin{array}{l}\text { Founded in } 2011 \text {, LACI is a cluster-driven } \\
\text { forum to support economic development in } \\
\text { LA. It covers multiple verticals (to drive } \\
\text { LA's green economy). Supported by public } \\
\text { agencies in LA. }\end{array}$ \\
\hline $\begin{array}{l}\text { EvoNexus (EN), } \\
\text { San Diego, CA, } \\
\text { USA }\end{array}$ & $\begin{array}{l}\text { Founded in } 2010, \text { EN is a business } \\
\text { accelerator that covers multiple verticals } \\
\text { (mobility and logistics). Supported by } \\
\text { private sector memberships. }\end{array}$ \\
\hline
\end{tabular}

Table 2. Independent incubators in the study.

The data was transcribed and summarized into ten case logs (memos) [29, 30]. Analysis was performed through a two-step process to explore to what level and how independent incubators support digital innovation. In the first step each of the nine unit of analysis was analyzed across the ten incubators separately. A threelevel scale was developed prior to the analysis to determine the level of support for digital innovation provided by each independent incubator. 'N/A,' 'Lim.,' and 'Ext.,' denote no apparent support, limited support (in terms of scope, depth, coverage, or time), or a wider range of support, respectively. Each case log was analyzed using the unit of analysis (Table 1) and the scale as lens by two of the researchers independently. Their results were then combined and compared. A "cross-case" assessment (Table 3) was consequently compiled through investigator triangulation [30]. In the second step, the output from the "cross-case" assessment was scrutinized, and operating models for incubators providing digital innovation support were discovered, labelled, and developed into concepts [29]. By diversifying the operating models based on level of digital innovation support $v s$ focus (either supporting the startup to evolve as venture or to improve its product) a matrix displaying the models concluded the second step of analysis (Figure 1).

\section{Results}

In this section the "cross-case" assessment (analysis step 1) is presented following the three categories in the analytic framework: innovation process, leadership and organization, and product to market. The comparison is displayed in Table 3.

\subsection{Innovation Process}

As discussed in previous sections, digital innovation from a process perspective entails recombination, digital resource design, and value space elaborations. The comparison suggests that independent incubators, generally speaking, aim to provide support in defining the value space as a part of providing business support.

Communitech (CT) provides three different acceleration programs targeting various types of startups with the explicit aim to map the value space for the product. Plug- $n$-Play (PnP) and Techstars Mobility (TM) provide similar programs, albeit of shorter durations and with less technical support; the focus is mainly on partner matchmaking. Their aim is to stimulate enrolled startups to better understand the value space where their solutions would fit and partners that could enable expansion in that space. $P n P$ and $T M$ provide extensive support to coach the startups on interactions (e.g., communicating their business plans) with potential customers, venture capitalists, and other relevant actors. The aim is to boost the capability within the startup to establish sustainable collaborations immediately after the accelerator program. A critical factor is that the startup company creates a capability to attract actors within the value space. Consequently, $P n P$ and $T M$ provide extensive support to charter the value space and to create partnerships, for example through coaching, limited initial financial incentives, courses, and other physical events.

Aiding value space exploration is a vital part of the support also offered by Creative Deconstruction Lab (CDL) and Sente Link (SL). However, these two incubators provide slightly different scopes and collaboration models than $P n P$ and $T M$ who primarily operate at a global level. $C D L$ and $S L$ aim to provide mentorship to define alternative value spaces for the startup digital resources, rather than detailing the value space initially defined by the startup. $C D L$ explicitly aim to recruit startups that have not solidified their financial models. So, by offering a program that deconstructs the original business model, the aim is to support it to charter new value spaces that are more promising. Hence, this program does not fit startups that have established business operations. The program includes a set of intense co-creation sessions where mentorship is provided in collaboration with relevant member partners to $C D L$. After a three-month introduction, the startups are reviewed to determine who should be allowed to stay in the program based on the most interest of the participating partners. This 
repetitive procedure reduces the number of enrolled startups, and gives more time for partner support to the remaining startups. SL, on the other hand, targets nonUS startups and offers them to scale their offerings on the US market. Consequently, there is less emphasis on the value space in the original region. Instead, mentoring is provided to support capturing the US market using Chicago and the state of Illinois as a point of entry.

Automation Alley (AA) is open both to US and international startups. It offers a seven-step mentor program to support startups to engage with companies in the automotive industry in and around Detroit. Extensive support is provided for exploring not only the originally targeted value space, but also new alternative areas. When compared to $C D L$ and $S L, A A$ has a much narrower focus, and it targets startups that aim to disrupt or add value to the manufacturing processes within the automotive industry, rather than customer-oriented digital solutions. This approach also maximizes the potential of $A A$ to deliver strong support within this niche. The goal is to accelerate business rather than strengthening technology readiness of the solutions.

Similar to SL, Nordic Innovation House (NIH) engages with startups that originate from Northern Europe. NIH provides an opportunity for Nordic startups to have a presence in Silicon Valley and does not explicitly mentor how to capture the US market.

\begin{tabular}{|c|c|c|c|c|c|c|c|c|c|c|c|c|}
\hline \multicolumn{3}{|c|}{ Analysis framework } & \multicolumn{10}{|c|}{$\begin{array}{l}\text { Comparison of independent incubators } \\
\text { Level of digital innovation support provided: } \\
\text { N/A = Not available I Lim. = Limited I Ext. = Extensive }\end{array}$} \\
\hline \multicolumn{2}{|c|}{ Unit of analysis } & $\begin{array}{c}\begin{array}{l}\text { What level of support does the incubator provide } \\
\text { to... }\end{array} \\
\end{array}$ & NIH & CDL & $\mathbf{A A}$ & SL & EN & PnP & TM & LACI & CT & \begin{tabular}{|l|} 
MV \\
FKA \\
\end{tabular} \\
\hline \multirow{8}{*}{$\begin{array}{l}\text { Innovation } \\
\text { Process [5] }\end{array}$} & \multirow{3}{*}{$\begin{array}{l}\text { Recombination } \\
{[15]}\end{array}$} & ...generate value paths via recombination? & N/A & N/A & $\mathrm{N} / \mathrm{A}$ & N/A & N/A & N/A & N/A & N/A & N/A & Lim. \\
\hline & & ...use available DR for recombination? & N/A & N/A & N/A & N/A & N/A & N/A & N/A & N/A & N/A & Ext. \\
\hline & & ...capture conn & $\mathrm{N} / \mathrm{A}$ & N/A & $\mathrm{N} / \mathrm{A}$ & $\mathrm{N} / \mathrm{A}$ & $\mathrm{N} / \mathrm{A}$ & N/A & N/A & N/A & N/A & Lim. \\
\hline & \multirow{3}{*}{$\begin{array}{c}\text { Digital resource } \\
{[15]}\end{array}$} & ...design a D & $\mathrm{N} / \mathrm{A}$ & $\mathrm{N} / \mathrm{A}$ & $\mathrm{N} / \mathrm{A}$ & $\mathrm{N} / \mathrm{A}$ & $\mathrm{N} / \mathrm{A}$ & N/A & $\mathrm{N} / \mathrm{A}$ & Lim. & Lim. & Ext. \\
\hline & & $\ldots$ desi & $\mathrm{N} / \mathrm{A}$ & $\mathrm{N} / \mathrm{A}$ & $\mathrm{N} / \mathrm{A}$ & $\mathrm{N} / \mathrm{A}$ & N/A & N/A & $\mathrm{N} / \mathrm{A}$ & Lim. & Lim. & Ext. \\
\hline & & 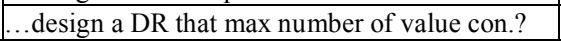 & N/A & N/A & $\mathrm{N} / \mathrm{A}$ & $\mathrm{N} / \mathrm{A}$ & $\mathrm{N} / \mathrm{A}$ & N/A & N/A & $\mathrm{N} / \mathrm{A}$ & Lim. & Lim. \\
\hline & \multirow{2}{*}{ Value space [15] } & ...define & Ext. & Lim. & Ext. & Ext. & Lim. & Ext. & Ext. & Ext. & Ext. & Lim. \\
\hline & & $\ldots \mathrm{de}$ & Ext. & Ext. & Ext. & Ext. & Ext. & Ext. & Ext. & Lim. & Lim. & $\mathrm{N} / \mathrm{A}$ \\
\hline \multirow{3}{*}{$\begin{array}{c}\text { Leadership } \\
\text { and } \\
\text { organization } \\
{[5]}\end{array}$} & & ...f foster a focus & N/A & N/A & $\mathrm{N} / \mathrm{A}$ & $\mathrm{N} / \mathrm{A}$ & Lim. & Lim. & Ext. & Lim. & Lim. & Ext. \\
\hline & Collaboration [10] & ...catalyze external collaboration? & Lim. & Lim. & Lim. & Lim. & Lim. & Ext. & Ext. & Ext. & Ext. & Lim. \\
\hline & Governance [10] & ...govern progress during DI? & N/A & Lim. & Lim. & Lim. & Lim. & Lim & Lim. & Ext. & Ext. & Ext. \\
\hline \multirow{9}{*}{$\begin{array}{l}\text { Product to } \\
\text { market [5] }\end{array}$} & \multirow{3}{*}{$\begin{array}{c}\text { Data-driven } \\
\text { operations [13] }\end{array}$} & ...profile actors through data-c & $\mathrm{N} / \mathrm{A}$ & N/A & $\mathrm{N} / \mathrm{A}$ & $\mathrm{N} / \mathrm{A}$ & N/A & Ext. & Ext. & N/A & N/A & Ext. \\
\hline & & ...assess risks through data-d & N/A & N/A & $\mathrm{N} / \mathrm{A}$ & $\mathrm{N} / \mathrm{A}$ & N/A & N/A & $\mathrm{N} / \mathrm{A}$ & N/A & N/A & Ext. \\
\hline & & ...monitor the & N/A & N/A & $\mathrm{N} / \mathrm{A}$ & $\mathrm{N} / \mathrm{A}$ & $\mathrm{N} / \mathrm{A}$ & $\mathrm{N} / \mathrm{A}$ & N/A & $\mathrm{N} / \mathrm{A}$ & $\mathrm{N} / \mathrm{A}$ & Ext. \\
\hline & \multirow{3}{*}{ Instant release $[13$} & ...launch the DR? & $\mathrm{N} / \mathrm{A}$ & $\mathrm{N} / \mathrm{A}$ & $\mathrm{N} / \mathrm{A}$ & $\mathrm{N} / \mathrm{A}$ & N/A & N/A & $\mathrm{N} / \mathrm{A}$ & Lim. & Lim. & Ext. \\
\hline & & \begin{tabular}{|l}
..perform concurrent trialing $\mathrm{c}$ \\
\end{tabular} & $\mathrm{N} / \mathrm{A}$ & N/A & N/A & $\mathrm{N} / \mathrm{A}$ & N/A & N/A & $\mathrm{N} / \mathrm{A}$ & Lim. & Lim. & Ext. \\
\hline & & ...do reactive modification of the DR? & $\mathrm{N} / \mathrm{A}$ & N/A & $\mathrm{N} / \mathrm{A}$ & N/A & $\mathrm{N} / \mathrm{A}$ & N/A & N/A & N/A & N/A & Ext. \\
\hline & \multirow{3}{*}{$\begin{array}{c}\text { Swift } \\
\text { transformation } \\
{[13]}\end{array}$} & ...conceptualize the DR for new bus. contexts? & Ext. & Lim & Ext & Ext & Ext. & Ext. & Ext. & Ext. & Ext. & N/A \\
\hline & & \begin{tabular}{|l}
.. identify novel benefits of a DR for customers? \\
\end{tabular} & Ext. & Ext. & Ext. & Ext. & Ext. & Ext. & Ext. & Ext. & Ext. & Ext. \\
\hline & & ...(re)define & Lim. & Ext. & Lim. & Lim. & Ext. & Lim. & Lim. & Ext. & Lim. & Ext. \\
\hline \multicolumn{3}{|r|}{ Discovered operating models } & \multicolumn{4}{|c|}{ Mentor } & \multicolumn{3}{|c|}{ Matchmaker } & \multicolumn{2}{|c|}{ Facilitator } & Enabler \\
\hline
\end{tabular}

Table 3. Comparison of the level of digital innovation support provided by 10 incubators.

Instead, NIH offers startups short-term accelerator programs to better define the value spaces, explore new areas and connect to different ecosystems.

The "cross-case" comparison revealed that incubators provide support for digital innovation with variations in scope, range and depth. Only three of them provide tangible support in the effort to design or recombine digital resources. $C T$ does this in a limited way by providing a physical innovation space where startups are hosted in the same facilities as growth- and established firms run innovation projects outside their ordinary operations. This co-location creates an environment that facilitates not only business acceleration but also the design and recombination of digital resources. The provision of this co-working environment is facilitated by teams that support the participants. Consequently, this support goes beyond business mentoring and includes design assistance and validation.

LA Cleantech Incubator (LACI) provides similar facilitation support that goes beyond business mentoring. The $L A C I$ facility provisions tools and infrastructure for the startups to develop and validate their products. Technology readiness is calibrated by a scale [32] to monitor and coordinate the progress of the different firms in the incubator, thereby making the resource provisioning more efficient. 
Motus Ventures together with FKA Silicon Valley (MV FKA) operates the model that provides the most extensive technology support beyond business related support (i.e., mentoring and partner matchmaking). The idea is to engage with startups within the narrow vertical of autonomous systems. The enrolled startups work with a limited set of anchor partners. Autonomous system solutions necessitate extensive testing and verification during/after technology integration, and the $M V F K A$ set up makes this cycle shorter and more robust. So, while $M V F K A$ offers limited support for growing the startup company as an independent company, it integrates them into a welldefined ecosystem. MV FKA also offers a common hardware/software benchmarking platforms for product development. Lastly, the FKA domain expertise aids with technology integration activities.

\subsection{Leadership and Organization}

The provision of additional support in relation to digital innovation becomes even more evident when comparing the cases using leadership and innovation as a unit of analysis. For example, the support provided by $M V F K A$ is more flexible way technology development than the traditional automotive engineering process. Extensive use of simulation-based approaches allows exploration of design patterns as a basis for digital innovation in an unconstrained manner. On the other hand, incubators that focus on mentoring and matchmaking do not enhance the technology readiness of the digital innovation. These incubators catalyze external collaboration involving the startups with other companies, venture capitalists, service providers, etc. $P n P, T M$, and $E N$ organize physical events to promote networking between the startups in their incubators and their dues-paying members to initiate collaborative tech and business ventures. $P n P$ takes this a step further when it offers its dues-paying members a "brokering" service to match their tech and business needs with the capabilities of startups in their incubator programs. The next step could be a collaborative pilot project that may grow to become something bigger. $C T$ offers dedicated teams to support the startups needs during the different stages of its growth. For example, the 'strategic growth teams' facilitates co-creation, handles IP and other contract matters, and a business coach. The 'corporate innovation teams' focus on membership partners, i.e., large organizations beyond a growth stage to support them to manage shifts in becoming more innovative by absorbing knowledge and results from the innovation programs hosted in the facilities provided by $C T$.

\subsection{Product to Market}

When addressing the unit of analysis product to market it became evident that independent incubators in general are effective for scaling startups in terms of swift transformation, but less effective in supporting instant release and data-driven operations. $P n P$, and to some extent $T M$, differ with respect to data-driven operations as they both offer extensive databases to profile and match startups with membership partners based on needs versus capability. This capability can be re-directed so that startups with a valuable digital resource are supported to rapidly find the right member partner to collaborate with in order to scale the digital resource offered. With respect to instant release [13], $C T$ and $L A C I$ are limited in their abilities to support the startups launch concurrent trials of digital resources.

The exception is $M V L K A$ where the operating model emphasized integration. Limited number of member partners with strong connections to the incubator have the potential to enable data-driven scaling of products to market. The strong links established between the incubators, the startups, the member partners, and an intermediary organization (e.g., a research institute) favor open access to the vast amount of data sources possessed by incumbent member firms. This permits not only support to profile customers, but also advanced data-driven support in assessing risks related to scaling of the product. It also enables monitoring how actual customers perceive the digital resources as it is integrated into vehicles and evaluated by actual end-customers in different settings. These strong links also support the startup launch concurrent trials and modifications to the digital resource. Two key features enable this. First, the intermediary part involved (e.g., the research institute) can relieve the member partner (such as an OEM) by providing authoritative domain expertise and a flexible work model that adheres to automotive industry standard. Second, the incubator is funded by the membership dues, and so the members are fully invested for success. While a part of the membership dues is used to cover the incubator operating costs, the rest is used for investing in the startups that are admitted into the incubator. The latter creates strong early links between the involved actors that on the one hand strengthen the capability to perform digital innovation with a greater commercialization prospects. On the other hand, it may hinder the startup/members from re-thinking or applying the innovation pieces to other business areas.

\section{Four Operating Models}

The "cross-case" comparison resulted in the discovery of four operating models for independent incubators supporting digital innovation (see bottom line in Table 3); i.e., independent incubators champions digital innovation differently. 


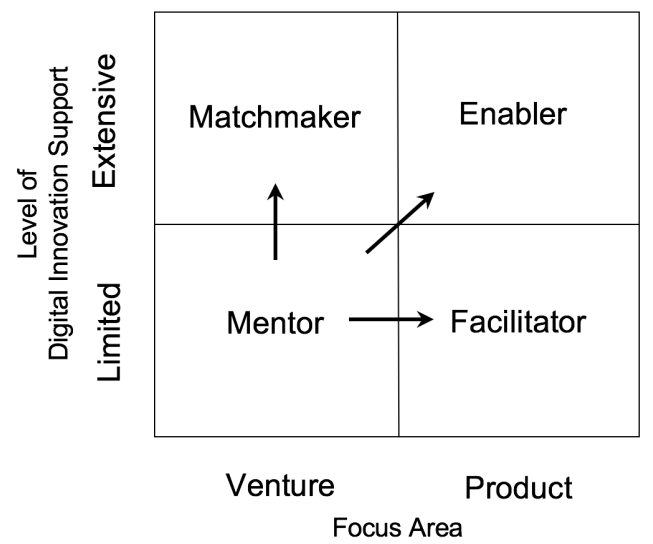

Figure 1. Four operating models.

Independent incubators in general provide some form of business venture support such as mentoring startups to evolve from an early venture into a viable growing business. However, depending on the digital innovation support and focus areas, there are four distinct operating models as shown in Table 3 and Figure 1. The arrows highlight that these operating models derives from the mentor model. To meet the objectives of the startup company, ventures or product readiness, the mentor model may be sufficient, or required one of the other models. The models are not mutually exclusive, but possess different primary facets.

\subsection{Mentor}

In this model, the startups evolve into ventures that operate as viable business operations with a first customer or a pilot collaboration project established. The distinguishing feature is mentorship. The support provided in terms of digital innovation is focused on value space mentoring in a current space or the exploration of alternative value spaces. The incubator provides conditions for evolving innovation collaboration in the form of connections to established networks. Support for scaling product to market by defining customer benefits and conceptualization of new business areas for the digital resource are also offered in this model.

\subsection{Matchmaker}

In this model, startups are transformed into scaled ventures operating in defined value space as contributing parts of an ecosystem. This model does not offer support that actually intervenes in the evolving the digital product. The Matchmaker model focuses on driving business ventures, identical to the Mentor model, but also provides extensive support related to widening the value space, increasing innovation collaboration, and support scaling through matching startups with other relevant actors in one or more value spaces. The incubators offer prospects of matching startups with partners globally. In addition to supporting startups during a limited time period, the Matchmaker model may also sustain the venture in its own ecosystem. This is often accompanied with acquiring an equity stake in the startup company that may impact the "autonomous" startup operations.

\subsection{Facilitator}

In this model, startups evolve into viable business ventures and their digital products mature in terms of technology readiness. Neither of the previously discussed models actively promotes technology development in terms of support recombining, redesigning or testing the digital resource. As these incubators often cover multiple verticals of innovation, this support in the form of human personnel and other resources is often restricted in terms of complexity and integration. This due to high costs associated with attracting and retaining domain expertise and other infrastructure costs.

\subsection{Enabler}

In this model, startups evolve into digital ventures with products that are integrated with platforms operating in a well-defined value space. This is because Enabler incubators support technology integration with proprietary, commercial platforms (e.g., a real vehicle platform) by focusing on one vertical (e.g., mobility) and collaborating with a limited number of industry-based domain experts. They support recombination, design, instant release, and concurrent testing through their strong links with the industry partners. Innovation governance is supported by provision of work practices that adhere both to the more creative and free workflow of the startup, and to the traditional engineering practice of a large corporation. Such methodology is complemented with mentors with different digital innovation capabilities in the defined value space.

\section{Discussion}

We propose four operating models for broadly characterizing digital innovation championed by independent incubators. While the models do not challenge the very 'definition' of incubators [11, p.13], they provide deeper insights into how digital innovation is supported differently through operating models with varying primary features. As the unique properties of digital solutions put new demands on innovation management [3], incubators have developed processes for helping digital ventures increase their value connections and for exploring new value spaces 
[15] and contexts to get more mileage out of their digital solutions. Networking and connecting to external business ecosystems are extremely important, and therefore the ability of incubators to provide this support becomes more important. Digital innovation also implies that the incubators may become more data-driven to identify new ventures and connections between the actors to support development and scaling. The possibility of instantly releasing prototypes and gain experience from the market makes it possible to evaluate digital ventures quickly. This implies that existing capabilities must be adapted (e.g., revised mentor profiles) and new capabilities have to be acquired (e.g., to act data-driven).

Typically, incubators follow two paths for technology development. One path is to emphasize connections to other actors and digital resources, excelling in matchmaking. Another path is to become more knowledgeable about digital technology and provide better technical support to startups. A 'third' path is the combination of networking and integration of digital solutions. We call these three models Matchmaker, Facilitator, and Enabler. The fourth model, Mentor, is a more classical type of incubator with shorter programs and a business focus on digital ventures. It is the starting point from which the other three roles differentiate themselves.

How can these lessons be transferred to a corporate incubator in traditional automotive settings with a focus on digital ventures? The first important aspect of corporate incubators is to provide a shield from the complexity and slow decision-making of the corporation [6]. It is clear that the three models Mentor, Facilitator, and Matchmaker - provide such a shield. However, the Enabler model aims to better integrate the digital resources with the in-house technology (of the corporation) and relies on access to technical equipment and test environments that necessitates a tighter working relationship.

A second aspect is to find individual champions (in the larger firm) who are able to give support to startups while tackling corporate complexity and connecting with relevant stakeholders inside the corporation [6]. As OEMs try to build competence in digital innovation it could be difficult to find these champions. Even when champions have been identified, it may not be easy to drive the innovation agenda due to the organizational rigidity or the nature of the industry. While internal candidates may have a strong network in the company, they may not possess the desired experience with digital innovation. On the other hand, external candidates may possess the desired experience, but will not have as strong of a network in the company. So, a solution could be to form teams of champions comprising the right mix of internal and external candidates.

A third aspect is to provide intensive mentoring and education programs that adhere to emerging concepts within the field of digital innovation. This is something corporate incubators can learn from the programs offered by Matchmakers and Mentors. These programs are often shorter than the Facilitator and Enabler programs and promote group dynamics by admitting cohorts of startups to interact with domain experts from the OEMs exploring and discover the potential with digitalization.

The final aspect is the ability of the incubators to promote networking within and to help incubates connect to external business ecosystems. Matchmakers and Facilitators have developed strong capabilities in this regard, while the Enabler is more restricted due to its focus on a particular industry domain. In terms of corporate involvement in the ventures [7], Enablers are most tightly involved while Facilitators and Mentors are more loosely involved. Matchmakers fall somewhere in between the two, meaning high level of involvement up till the point of a successful match.

So, by performing qualitative interviews following an interview guide anchored in digital innovation literature, we have been able to compare and categorize the ten incubators that were surveyed in North America. The incubators were selected according to criterion-based sampling. It is remarked that the case context is highly relevant to the automotive industry that limits the transferability of these results to other industry domains. The research methodology has been documented for dependability and replication.

\section{Conclusions}

We conclude that independent incubators specializing in digital ventures handle digital innovation differently according to focus areas and levels of support. Based on these variables we define four types of independent incubators - Mentor, Matchmaker, Facilitator, and Enabler. As OEMs aim to champion digital innovation by establishing corporate incubators, it is vital to shield the ventures/startups from its intrinsic complexities, set up teams of champions and mentoring programs, and forge a medium to plug into larger business ecosystems. As future work, it is proposed to explore the design of automotive corporate incubators to accelerate digital innovation by balancing the spirit of digital entrepreneurship and the corporate mindset.

\section{References}

[1] Yoo, Y., Henfridsson, O., \& Lyytinen, K. (2010). Research commentary - the new organizing logic of digital 
innovation: an agenda for information systems research. Information systems research, 21(4), 724-735.

[2] Athanasopoulou, A., Bouwman, H., Nikayin, F., \& de Reuver, M. (2016). The disruptive impact of digitalization on the automotive ecosystem: a research agenda on business models, platforms and consumer issues. In Proceedings of the 29th Bled eConference: Digital Economy, 597-604.

[3] Nambisan, S., Lyytinen, K., Majchrzak, A., \& Song, M. (2017). Digital innovation management: Reinventing innovation management research in a digital world. Mis Quarterly, 41(1).

[4] Dodourova, M., \& Bevis, K. (2014). Networking innovation in the European car industry: Does the Open Innovation model fit? Transportation Research Part A: Policy and Practice, 69, 252-271.

[5] Juell-Skielse, G., \& Hjalmarsson-Jordanius, A. (2017). Accelerating Open Digital Innovation in the Automotive Industry: Action Design Research in Progress. Association for Information Systems.

[6] Kohler, T. (2016). Corporate accelerators: Building bridges between corporations and startups. Business Horizons, 59(3), 347-357.

[7] Weiblen, T., \& Chesbrough, H. W. (2015). Engaging with startups to enhance corporate innovation. California Management Review, 57(2), 66-90.

[8] Burr, W., Valentowitsch, J., \& Bosler, M. (2017). Neuartige Formen der Kooperation mit dem Startup Sektor. In Innovative Produkte und Dienstleistungen in der Mobilität (pp. 87-99). Springer Gabler, Wiesbaden.

[9] Mian, S., Lamine, W., \& Fayolle, A. (2016). Technology Business Incubation: An overview of the state of knowledge. Technovation, 50, 1-12.

[10] Svahn, F., Mathiassen, L., \& Lindgren, R. (2017). Embracing Digital Innovation in Incumbent Firms: How Volvo Cars Managed Competing Concerns. Mis Quarterly, 41(1).

[11] Hausberg, J. P., \& Korreck, S. (2018). Business incubators and accelerators: a co-citation analysis-based, systematic literature review. The Journal of Technology Transfer, 1-26.

[12] Yoo, Y., Boland Jr, R. J., Lyytinen, K., \& Majchrzak, A. (2012). Organizing for innovation in the digitized world. Organization Science, 23(5), 1398-1408.

[13] Huang, J., Henfridsson, O., Liu, M. J., \& Newell, S. (2017). Growing on Steroids: Rapidly Scaling the User Base of Digital Ventures through Digital Innovation. MIS Quarterly, 41(1).

[14] Meyer, M. H., \& Webb, P. H. (2005). Modular, layered architecture: the necessary foundation for effective mass customisation in software. International Journal of Mass Customisation, 1(1), 14-36.

[15] Henfridsson, O., Nandhakumar, J., Scarbrough, H., \& Panourgias, N. (2018). Recombination in the open-ended value landscape of digital innovation. Information and Organization, 28(2), 89-100.
[16] Olsson, H. H., \& Bosch, J. (2014). Ecosystem-driven software development: a case study on the emerging challenges in inter-organizational R\&D. In International Conference of Software Business (pp. 16-26). Springer International Publishing.

[17] Henfridsson, O., \& Lindgren, R. (2010). User involvement in developing mobile and temporarily interconnected systems. Information Systems Journal, 20(2), 119-135.

[18] Ili, S., Albers, A., \& Miller, S. (2010). Open innovation in the automotive industry. R\&D Management, 40(3), 246255.

[19] Cooper, R. G. (1990). Stage-gate systems: a new tool for managing new products. Business horizons, 33(3), 44-54.

[20] Cabigiosu, A., Zirpoli, F., \& Camuffo, A. (2013). Modularity, interfaces definition and the integration of external sources of innovation in the automotive industry. Research Policy, 42(3), 662-675.

[21] Colfer, L., \& Baldwin, C. Y. (2010). The mirroring hypothesis: Theory, evidence and exceptions. Harvard Business School Finance Working Paper, (10-058).

[22] Govindarajan, V., \& Trimble, C. (2010). The other side of innovation: Solving the execution challenge. Harvard Business Press.

[23] Köhler, J., Schade, W., Leduc, G., Wiesenthal, T., Schade, B., \& Espinoza, L. T. (2013). Leaving fossil fuels behind? An innovation system analysis of low carbon cars. Journal of Cleaner Production, 48, 176-186.

[24] Henderson, R., \& Clark, K. B. (1989). " Generational" innovation: the reconfiguration of existing systems and the failure of established firms. Working Paper Alfred P. Sloan School of Management.

[25] Grimaldi, R., \& Grandi, A. (2005). Business incubators and new venture creation: an assessment of incubating models. Technovation, 25(2), 111-121.

[26] Ford, S., Garnsey, E., \& Probert, D. (2010). Evolving corporate entrepreneurship strategy: technology incubation at Philips. R\&D Management, 40(1), 81-90.

[27] Christensen, C. (2013). The innovator's dilemma: when new technologies cause great firms to fail. Harvard Business Review Press.

[28] Jensen, J. L., \& Rodgers, R. (2001). Cumulating the intellectual gold of case study research. Public Administration Review, 61(2), 235-246.

[29] Rubin, H. J., \& Rubin, I. S. (2012). Qualitative Interviewing: The Art of Hearing Data 3rd ed. Sage Publications Inc.

[30] Patton, M. Q. (2005). Qualitative research. John Wiley \& Sons, Ltd.

[31] Sein, M. K., Henfridsson, O., Purao, S., Rossi, M., \& Lindgren, R. (2011). Action Design Research. MIS Quarterly, 35(1), 37-56.

[32] Mankins, J.C. (1995). Technology Readiness Levels: A White Paper. Office of Space Access and Technology, NASA. 